NBER WORKING PAPER SERIES

\title{
THE TRICK IS TO LIVE: IS THE ESTATE TAX SOCIAL SECURITY FOR THE RICH?
}

\author{
Wojciech Kopczuk \\ Working Paper 9188 \\ http://www.nber.org/papers/w9188 \\ NATIONAL BUREAU OF ECONOMIC RESEARCH \\ 1050 Massachusetts Avenue \\ Cambridge, MA 02138 \\ September 2002
}

I thank Roger Gordon, Joel Slemrod, Jim Hines, John Laitner, Varsha Venkatesh, Douglas Holtz-Eakin, participants of seminars at the University of Michigan, University of British Columbia, Yale, Columbia, Northwestern, Chicago GSB, Stanford GSB, Cambridge, Stockholm University and NTA for helpful comments. The views expressed herein are those of the author and not necessarily those of the National Bureau of Economic Research.

(C) 2002 by Wojciech Kopczuk. All rights reserved. Short sections of text, not to exceed two paragraphs, may be quoted without explicit permission provided that full credit, including (C) notice, is given to the source. 
The Trick is to Live: Is the Estate Tax Social Security for the Rich?

Wojciech Kopczuk

NBER Working Paper No. 9188

September 2002

JEL No. H2

\title{
ABSTRACT
}

Because estate tax liability usually depends on how long one lives, it implicitly provides annuity income. In the absence of annuity markets, lump-sum estate taxation may be used to achieve the first-best solution for individuals with a sufficiently strong bequest motive. Calculations of the annuity embedded in the U.S. estate tax show that people with $\$ 10$ million of assets may be effectively receiving more than $\$ 100,000$ a year financed at actuarially fair rates by their tax payments. According to my calibrations, the insurance effect reduces the marginal cost of funds (MCF) for the estate tax by as much as $30 \%$ and the resulting MCF is within the range of estimates for the marginal cost of funds for the income tax.

\author{
Wojciech Kopczuk \\ Department of Economics \\ University of British Columbia \\ 997-1873 East Mall, Vancouver, BC V6T1Z1 \\ Canada \\ and NBER \\ wkopczuk@nber.org
}


"The trick is to live."

Small business owner Sandy Graffius on her strategy for avoiding the estate tax. ${ }^{1}$

\section{Introduction}

Should the rich favor the repeal of the estate tax? Not necessarily. By postponing tax payments until death, estate taxation may act like social security by reducing the present value of lifetime tax liability the longer one lives. To the extent that people subject to the estate tax do not face

actuarially fair insurance markets, ${ }^{2}$ it may make perfect sense to raise at least part of tax revenue in the form of an estate tax. The key insight is that estate taxation can bring about a transfer from the (ex-post) short-living to long-living individuals. Assuming a risk-neutral government (or, simply, no aggregate mortality risk), the government may be able to transfer resources between different states of the world at actuarially fair rates without any loss in revenue (and thus without increasing the present value of taxes paid by a given individual). Consequently, estate taxation may serve as a substitute for private annuity markets and social security.

The paper makes three basic points. In theory, the estate tax may play an insurance role. In practice, the actual U.S. estate tax provides a sizable annuity to the estate taxpayers. Furthermore, the presence of annuity significantly reduces the efficiency cost of this tax instrument.

The basic intuition for understanding the role of taxes imposed on (partially) accidental bequests is as follows. Because the estate tax is conditional on death, it has the same flavor as life insurance, except with the opposite sign. Individuals who would like to take a short position on life insurance, but are unable to do so because of market imperfections, should thus welcome converting their tax liability into an estate tax. In particular, the government may be able to make this conversion actuarially fair because it weighs tax receipts by survival probabilities. As argued by Bernheim (1991), purchases of life insurance may be used to offset the effects of purchases of annuities, and vice versa. Thus, estate taxation has an aspect of annuities embedded into it. More specifically, if estate tax payments fall with age (in the present value sense), survival entails tax savings and therefore the tax provides a positive annuity.

It is widely believed that at least part of the estates that people leave is not planned, but instead is due to lifetime savings that are not consumed because of uncertainty about the length of life. This observation has led some to suggest that if taxpayers are lifetime savers only, the estate tax is quite efficient: there is no behavioral response because no decisions made during lifetime

\footnotetext{
${ }^{1}$ Quoted in Newsweek, June 19, 2000 p. 21.

${ }^{2}$ The price of insurance is actuarially fair if the expected value of the contract is zero.
} 
are distorted. This suggests a "free lunch", a rare phenomenon in economics. At first blush this argument seems reasonable, but it contains a fallacy. "Accidental" bequests are a symptom of some underlying market imperfection (most likely in the annuities markets), and the first-best solution is to correct the imperfection (and thereby eliminate accidental bequests altogether). Only when the first-best solution is not feasible do accidental bequests arise. Then, $100 \%$ taxation of accidental bequests may have no direct efficiency cost, but providing an annuity generates an efficiency gain. The lack of behavioral response when accidental bequests are present is misleading. Compared to the first-best optimum (arising when insurance contracts are priced actuarially fairly), relative prices and individual behavior are distorted. Therefore, compared to the first-best optimum, taxation of accidental bequests is not without a welfare loss.

There is, however, a grain of truth behind the argument that taxes imposed on accidental bequests are particularly efficient. The revenue generated from taxes on accidental bequests can be used to finance reduced taxes while alive, thereby providing an implicit annuity. This transfer across different states is preferred by consumers who would like to purchase annuities, although it is limited by the amount of life-cycle saving that individuals are willing to undertake. If it was possible to commit an individual to save enough to cover any required level of estate tax liability, estate taxation could be used to achieve the first-best solution by (1) forcing individuals to save the right amount in the early periods (it is possible if people have to meet the required level of estate tax liability) and (2) using tax policy to reallocate resources across different states of the world at actuarially fair rates, so that the resulting allocation is on the utility possibility frontier.

Similar reasoning applies to individuals with a bequest motive. However, in this context it is easier to provide an incentive mechanism that would make individuals save to meet the required level of estate tax liability: if a bequest motive is sufficiently strong, people will want to save to leave a bequest regardless of the taxes imposed on them. The paper demonstrates that the estate tax alone may then be used to achieve the first-best solution, even when the actuarially fair markets for annuities are non-existent.

Arguably, the Social Security system does not attempt to provide significant annuities for the rich. For the highest incomes the replacement rate is $15 \%$, compared to $90 \%$ for the lowest one. Furthermore, a portion of Social Security income is subject to (progressive) income taxation. The nominal progressive structure of the Social Security benefits is mitigated by the lower mortality of the rich $^{3}$ and by limiting the maximum amount of income subject to Social Security taxes $(\$ 76,200$ in 2000). Most importantly, however, the maximum annuity provided by the Social Security system is small. The Primary Insurance Amount ${ }^{4}$ (PIA) in 1997 was $\$ 1,326$ for workers whose earnings were at or above the maximum amount that counted for contribution and benefit purposes each

\footnotetext{
${ }^{3}$ See Attanasio and Hoynes (2000) and the papers cited there.

${ }^{4}$ This is the upper bound of monthly benefits per spouse from the Social Security.
} 
year and who retired in 1997 (Social Security Administration 1997, p. 18). It is implausible that even the maximum annuity payable by the Social Security system fulfills the need of the rich to annuitize. The evidence cited later in the paper suggests that it is also not possible to purchase private annuities at fair prices. This paper suggests that the presence of estate taxation to some extent alleviates this problem.

The plan of the paper is as follows. Section 2 discusses how the government may provide annuities in a number of different ways, Social Security being just one of them. In particular, it is possible to replicate any annuity by using stylized estate taxation. In Section 3, it is demonstrated, in a single individual context, that lump-sum estate taxation can sometimes be used to reach the first-best optimum. The main obstacle is the presence of "moral hazard." Using estate taxation to implement annuities amounts to an ex post payment for the insurance contract, and individuals may not have the appropriate incentives to hold a large enough estate to finance it. This problem is inherent if people save only for life-cycle purposes, but I show that it does not arise if bequest motives are strong enough. Even an estate tax that is not lump-sum still provides an annuity. In Section 3.1, it is demonstrated that when insurance markets are missing, the optimal marginal estate tax rate can be positive even when regular lump-sum taxation is possible and people have a bequest motive.

The last portion of the paper investigates local optimality of the current U.S. estate tax. In Section 4.1, the amount of annuity embedded in the U.S. estate tax system is quantified. The following calculations use the concept of the marginal cost of funds (MCF) to pin down the quantitative importance of the insurance effect. The calibration suggests that MCF for the estate tax is of the same order as the marginal cost of funds for the income tax. According to my calculations, the insurance effect contributes to a reduction in the MCF by between four and thirty-five percent, depending mostly on the degree of imperfection in the annuity markets. The last section concludes.

\section{Estate Tax as an Insurance Contract}

I begin by showing the relationship between streams of annuity and estate tax payments. Assuming away uncertainty other than mortality risk, different dates of death directly correspond to different resolutions of uncertainty, even though the context is intertemporal. A stream of annuity payments determines the pattern of transfers between different states of the world. In a nutshell, the discussion in this section exploits the possibility of re-timing these transfers without affecting their stochastic properties.

Consider a representative individual who has probability $p_{s}$ of survival until period $s, s=$

$0, \ldots, I$, with $p_{0}=1$. Suppose that the government wishes to provide a stream of annuity payments of $A_{s}, s>0$ (i.e., conditional on survival until period $i$ the individual would receive $A_{s}$ ), financed by tax revenue with a zero revenue requirement in present value. For now, the focus is on the accounting 
transformations of the annuity stream, without regard for a potential behavioral response.

Regardless of the details of its implementation, such a policy must involve a stream of expenditures $\left\{A_{s}\right\}$ that occur with probabilities of $\left\{p_{s}\right\}$, financed by unconditional tax payments with the present value of $T$ as of the initial period. Note that, with a single individual and no administrative costs, provision of $\left\{A_{s}\right\}$ is going to be an actuarially fair contract when the government is risk neutral or there is no aggregate mortality risk: $T=\sum_{s=1}^{I} p_{s}(1+r)^{-s} A_{s}$, because the government uses survival rates to discount future expenses. Interestingly, actuarial fairness of such an annuity does not depend on the lump-sum character of payments. Neither the incentives faced by an individual, nor the way the revenue is collected and transfers implemented matter, as long as the effective transfers conditional on different resolutions of uncertainty are as given by $\left\{A_{s}\right\}$.

Such a stream of annuity payments may be structured in many different ways. One way is straightforward: an initial ${ }^{5}$ tax payment of $T$ followed by subsidies conditional on survival as it is the case with privately purchased annuities or the actual Social Security system (of course, the real-life solutions are not necessarily actuarially fair). Many alternative ways of structuring the annuity payments may be designed by changing the timing of tax payments. Consider, for example, introducing a tax of $(1+r)^{s} T$ payable in case of death in period $s$, while holding annuity payments $A_{s}$ as before. Since death occurs with certainty and the present value of tax receipts under any resolution of uncertainty is exactly $T$, this is an unconditional tax collecting exactly $T$. Therefore, net transfers received are always exactly the same as with explicitly provided annuities.

An implementation of the annuity payments that is most important for this paper relies on estate taxes and an initial tax combined. In discussion of this policy a simple lemma (demonstrated in the appendix) will prove helpful.

Lemma 1 Consider two possibilities: (a) a lump-sum tax of $E_{s}$ conditional on dying at the end of period $s$; and (b) a lump-sum tax of $E_{s}$ conditional on having survived until period $s$ combined with a lump-sum transfer of $(1+r) E_{s}$ conditional on having survived until period $s+1$. The sets of feasible consumption/bequest plans in these two cases are identical.

The idea is to introduce an ex-ante lump-sum tax, and offer a refund only to the survivors. This lemma thus shows how a tax payment conditional on death may be transformed into payments and subsidies conditional on survival. Lemma 1 can be used to convert a stream of estate tax payments into annuities and vice versa. Consider an individual who at his current consumption plan will pay the estate taxes of $E_{s}, s=0, \ldots, I$, in case of death at the end of period $s$. His stream of potential tax payments may be equivalently given as a combination of an initial lump-sum tax and subsequent (positive or negative) annuity payments.

\footnotetext{
${ }^{5}$ What is important is that the tax is due before non-trivial death probabilities arise.
} 
Proposition 1 A stream of estate tax payments $\left\{E_{s}\right\}_{s=0, \ldots, I}$ is equivalent (i.e., yields the same tax payments under any resolution of uncertainty) to the initial lump-sum tax of $T=E_{0}$ and a stream of annuity payments $\left\{A_{s}\right\}_{s=1, \ldots, I}$, where $A_{s}=(1+r) E_{s-1}-E_{s}, s=1, \ldots, I$.

Proof: By Lemma 1, $E_{s}$ is equivalent to a change in $A_{s}$ of the amount $-E_{s}$ and a change in $A_{s+1}$ of $(1+r) E_{s}$. Aggregating this over $s$ yields the result. Note that it leads to $A_{0}=-E_{0}$ which is, equivalently, a tax in the amount of $E_{0}$.

The proposition states that the estate tax may always be expressed as a combination of a lump-sum tax and a series of annuity receipts or payments. From the proposition, it is easy to observe that the positiveness of annuity payments is equivalent to the present value of estate tax payments being a decreasing function of age at death. This has noteworthy implications. Simply observing the age profile of estate tax payments determines whether annuity payments are embedded in the estate tax. Note also that, although the equivalence in terms of budget sets depends on the lump-sum character of taxes, the decomposition of an estate tax into annuities does not. In other words, if the stream $\left\{E_{s}\right\}$ arose as the result of a distortionary tax policy, it would still insure the way an annuity does, although the incentives under the two scenarios might be quite different. In Section 4.1, Proposition 1 is used to quantify the annuity embedded in the U.S. estate tax.

Corollary 1 A stream of annuity payments $\left\{A_{s}\right\}$ and an initial tax of $T$ is equivalent to an estate tax $\left\{E_{s}\right\}$ defined by $E_{0}=T$ and $E_{s}=(1+r) E_{s-1}-A_{s}$.

The corollary simply states that the same transfers that take place under a Social Security system or private insurance schemes can also follow from a judicious choice of estate tax payments. This intuition will be used in what follows.

\section{Estate Taxation and Imperfect Annuity Markets}

A commonly suggested rationale for introducing Social Security is the presence of imperfections in the insurance markets. The purpose of this section is to show that estate taxation may help to resolve such market failure. I characterize the optimal estate tax policy and discuss the associated incentive problems in a formal model with a stylized set of lump-sum instruments available. Most importantly, I show that lump-sum estate taxation may in some circumstances be used to implement the first-best solution. ${ }^{6}$ In what follows, I take market imperfections as given, without modeling their underlying cause. ${ }^{7}$ This serves to highlight the insurance role of estate taxation and establish that it is indeed an alternative to other means of providing annuities.

\footnotetext{
${ }^{6}$ In an earlier version of this paper (Kopczuk 2001) it is demonstrated that when subsidies are possible the first-best solution can always be implemented using lump-sum estate taxation.

${ }^{7}$ One likely source is adverse selection: private markets may then be inefficient or cease to exist (Akerlof 1970; Rothschild and Stiglitz 1976). Government may then increase welfare by forcing everybody to participate and
} 
Suppose that an individual lives for at most two periods, with the probability of dying at the end of the first period being $1-p, 0<p<1$. There is no other uncertainty. There is an exogenously given level of first-period income $y$. The revenue requirement is $R$, but the government cares only about the expected present value of payments. There are two types of available tax instruments: an initial lump-sum tax and a lump-sum (estate) tax that is due when individual dies. What is the optimal way of collecting the required amount of revenue?

The first-best solution occurs when markets are actuarially fair, i.e., when the expected value of insurance contracts is zero. The optimal consumption/bequest plan in this case can be implemented by annuitizing lifetime consumption and using life insurance for bequests (Yaari 1965). ${ }^{8}$ The optimal way of collecting revenue is by unconditional lump-sum taxes. Such a solution will be compared with the solution when insurance markets are shut down and some alternative tax system is used. ${ }^{9}$ The assumption of no insurance markets is made for convenience (as in, e.g., Davies 1981; Hurd 1989), but the basic idea applies also to a more realistic case of imperfect insurance markets. ${ }^{10}$

Consider the utility function augmented by a "joy-of-giving" bequest motive,

$$
u\left(C_{1}\right)+(1-p) v\left(B_{1}\right)+p u\left(C_{2}\right)+p v\left(B_{2}\right),
$$

where $C_{i}, i=1,2$, is consumption in period $i, B_{i}$ is the bequest left in case of death at the end of period $i$ and $v(\cdot)$ is the utility derived from it. The interest rate is assumed to be zero, and there is no discounting other than implicitly through the survival rate. ${ }^{11}$

Suppose first that the individual does not have a bequest motive so that $v(B)=0$. The budget constraint is simply $C_{1}+C_{2}=y-T$, where $T$ is the initial lump-sum tax. This should be contrasted with the budget constraint when annuities are available and priced at $p$ (i.e., actuarially

offering, e.g., insurance at "average" rates to everyone. This market failure has been suggested as a justification for governmental intervention (Diamond 1977). The publicly provided Social Security benefits in the United States and many other countries limit the maximum amount of retirement income, so that they are unlikely to provide sufficient annuities for the well-off. This is also the group which is most likely to face estate taxation.

${ }^{8}$ If it is possible to choose a short position on one of these instruments, the optimal solution may be implemented by using it and regular saving. This equivalence breaks down when markets are imperfect (Bernheim 1991).

${ }^{9}$ There is a long line of literature dealing with the behavior of a consumer facing mortality risk (see e.g., Yaari 1965; Davies 1981; Abel 1985; Hurd 1989; Bernheim 1991). Some of these papers (Davies 1981; Abel 1985) consider accidental bequests in isolation, while others (Hurd 1989; Bernheim 1991) allow also for intentional bequests.

${ }^{10}$ Several studies have argued that private annuities are far from being fairly priced, and possibly should not be used by optimizing consumers. Friedman and Warshawsky (1990) concluded that annuities are dominated by other saving instruments. Using more recent data, Mitchell, Poterba, Warshawsky, and Brown (1999) find that the expected present discounted value of annuity pay-out is between 76 and 93 cents, depending on the mortality and interest rate assumptions. In their simulation, the optimizing consumer should make some use of these imperfect contracts.

${ }^{11}$ All the results in this section go through without these assumptions, although at the cost of additional notation. 
fairly), $C_{1}+p C_{2}=y-T$. As stated, an estate tax would play no role in the consumer's problem, because it does not in any way affect the budget set. When annuities are available, the optimal solution is given by $C_{1}^{*}=C_{2}^{*}=\frac{y-T}{1+p}$, and the individual always dies with zero wealth. The first-best policy is to set the lump-sum tax equal to the revenue requirement, $T=R$.

When markets for annuities are shut down, the optimal consumption plan features $u^{\prime}\left(C_{1}\right)=$ $p u^{\prime}\left(C_{2}\right)$. Under the standard assumption of decreasing marginal utility, this implies that $C_{1}>C_{2}$, regardless of the choice of tax instruments. Therefore, state-dependent lump-sum taxation cannot be used to reach the first-best allocation. In the optimal tax regime, the estate left in the case of death after the first period should be confiscated by the government. ${ }^{12}$ This is well-known, but interpretation of this result in terms of annuity provision is not: the policy of confiscating accidental bequests provides annuities. By relying in part on the tax imposed on the "accidental" bequest, the initial lump-sum tax can be set below the revenue requirement and the tax faced ex post by long-living individuals is reduced. Short-living individuals pay more in taxes (although they do not care about all of their tax payments) than long-living ones. This transfer is limited by the amount of saving in the first period, and it is insufficient for attaining the first-best allocation even though the estate tax can be nominally set to implement the first-best annuity (and any other annuity) using the scheme of Corollary 1 . In the life-cycle context, however, there are no incentive mechanisms that could force the individual to meet the necessary level of estate tax payments. In a richer setting, however, this problem may be overcome.

One such incentive mechanism may arise in the presence of a bequest motive (from now on, it is no longer assumed that $v(B)=0$ ). Because the government is trying to provide insurance financed by ex post estates, it faces the problem of moral hazard: individuals have an incentive to spend their estates. However, if the individual cares about leaving a positive bequest, a high estate tax may make him save enough to meet this requirement.

When markets are actuarially fair, the resulting allocation is the first-best solution to the individual's problem. The optimal tax policy is to impose a lump-sum tax collecting the required revenue. The budget constraint in this case is

$$
C_{1}+p C_{2}+(1-p) B_{1}+p B_{2}=y-R
$$

and, assuming an interior solution for bequests, the optimal allocation is characterized by $u^{\prime}\left(C_{1}\right)=$ $u^{\prime}\left(C_{2}\right)=v^{\prime}\left(B_{1}\right)=v^{\prime}\left(B_{2}\right)$. Denote this optimal solution by $\left(C_{1}^{*}, C_{2}^{*}, B_{1}^{*}, B_{2}^{*}\right)$.

Consider now the case when neither annuities nor life insurance are available. Denote by $E$ the estate tax due in case of death in the first period (if the estate is smaller than $E$, it is all

\footnotetext{
${ }^{12}$ Of course, it is going to affect the subsequent generation. I do not address the issue of optimal intergenerational transfers. There are other instruments that may be employed to transfer resources between generations without distorting life-cycle decisions such as, e.g., debt policy.
} 
confiscated). The estate tax in the second period is set to zero. There are two relevant constraints: the second-period constraint,

$$
C_{2}+B_{2}=y-T-C_{1},
$$

and the first-period resource constraint

$$
\begin{aligned}
& B_{1}+C_{1} \quad=\quad y-T-E, \\
& \text { or } \quad B_{1}=0 \text { and } \quad C_{1} \leq Y-T .
\end{aligned}
$$

Note that the consumer has an option of leaving no bequest and saving less than the estate tax due in the first period. This would increase first-period consumption above the level possible while holding bequests positive, by consuming a part of the would-be tax payment of $E$. The next proposition shows that when such a possibility may be excluded, it is possible to use estate taxation to arrive at the first-best allocation.

Proposition 2 Suppose that $v(0)=-\infty$. When the government sets $E=C_{2}^{*}+B_{2}^{*}-B_{1}^{*}$ and $T=y-C_{1}^{*}-C_{2}^{*}-B_{2}^{*}$, the resulting allocation is the first-best optimum and the revenue constraint clears.

Proof: Consider using the stated $E$ and $T$. Direct inspection of equations (3) and (4) shows that it makes the first-best solution feasible. Will it be selected? By assumption, $B_{1}=0$ is not optimal, because the utility level would be equal to negative infinity. By construction, any allocation $\left(B_{1}, C_{1}, B_{2}, C_{2}\right)$ with $B_{1}>0$ in the consumer's budget set satisfies the individual resource constraint. The revenue collected is $T+(1-p) E=y-C_{1}^{*}-(1-p) B_{1}^{*}-p C_{2}^{*}-p B_{2}^{*}$, i.e., it is equal to the revenue collected in the perfect markets setup. Thus, this allocation was also feasible in the first-best case, and so the first-best solution is revealed preferred to it. Therefore, the first-best allocation must be the optimum of the problem.

Remark 1 The estate tax identified in the proposition is positive. This is because $C_{2}^{*}>0$ and $v^{\prime}\left(B_{1}^{*}\right)=v^{\prime}\left(B_{2}^{*}\right)$ so that $B_{1}^{*}=B_{2}^{*}$.

Proposition 2 is a powerful result. Estate taxation alone is able to correct the imperfection in the annuities market and push the economy to the first-best optimum. The tax policy assumes the role of privately purchased insurance. The estate tax is used to transfer, in an actuarially fair way, resources from the people who die early to those who live relatively long. This is the same reallocation of resources between different states of the world as the one explicitly occurring in the first-best solution via purchases of insurance contracts. As explained in Section 2, it is also equivalent to appropriately designed publicly provided old-age benefits.

This solution has an intriguing feature: the prices of consumption and bequests are not affected so that, on the surface, the price incentives under the first-best and estate-tax regimes are different. 
Why is the same allocation selected in both cases? Essentially, this is the same effect as with Social Security: an implicit annuity embedded in the estate tax transfers resources between periods. Mechanically, under estate taxation there are two constraints that describe the budget set. The way they are stated (equations 3-4), first-period consumption appears in both of them, so that its marginal cost reflects the relative importance of both and is, in a way, endogenous. In the described solution this "price" replicates the first-best incentives. Notably, even though an imperfection is present the proposed solution is not a Pigouvian tax. It is also unlike direct regulation, because consumers are not explicitly constrained in their decisions. The lack of annuities is better thought of as a failure on the production side of economy: the technology to convert consumption in one state of the world to consumption in the other state is not available. Estate taxation provides this otherwise infeasible technology and moves the economy to the production possibility frontier.

The assumption of $v(0)=-\infty$ in Proposition 2 is unnecessarily strong. ${ }^{13}$ It implies that individuals always leave a bequest. The proof of Proposition 2 requires only comparing the firstbest allocation with a corner solution when the estate tax is avoided.

Remark 2 The assumption $v(0)=-\infty$ may be weakened. All that is required is that the utility in the first-best optimum is greater than the utility from choosing $B_{1}=0$ and the optimal selection of other variables subject to $C_{1}+C_{2}+B_{2}=y-T$, with $T$ given in the statement of the proposition.

\subsection{Linear Estate Tax}

The lump-sum character of assumed instruments was exploited in the proof of efficiency of estate taxation, Proposition 2. A practical estate tax, however, is unlikely to be either age-varying or lump-sum. Instead, it will be a non-constant function of estates or bequests, $E(B)$, with $E^{\prime}(B) \neq 0$. It is not difficult to show that such a tax will not, in general, be able to implement the first-best allocation. To see this, consider the previous setup. In the first-best optimum, $B_{1}^{*}=B_{2}^{*}$ : a consumer who is able to fully annuitize does not choose a time-varying pattern of bequests. ${ }^{14}$ If this allocation was feasible to implement using tax policy, the estate tax payments would not depend on the time of death $E\left(B_{1}^{*}\right)=E\left(B_{2}^{*}\right)$, and Proposition 1 implies that no annuity is provided by the estate tax

\footnotetext{
${ }^{13}$ This assumption is stronger than the more standard assumption of infinite marginal utility at zero, because it implies that the consumer is willing to sacrifice discrete amounts of other goods for a differential change in bequests at zero. Still, some commonly used utility functions have this feature. For example, the isoelastic utility function $v(x)=\frac{x^{1-\theta}}{1-\theta}$ satisfies this assumption for $\theta>1$.

${ }^{14}$ This is not true in general. If non-zero interest rate $(r)$ and discounting $(\rho)$ are introduced, the optimum must satisfy $v^{\prime}\left(B_{1}\right)=\frac{\rho}{1+r} v^{\prime}\left(B_{2}\right)$. This is the Euler equation, similar to the one that needs to be satisfied by consumption. Unless $\frac{\rho}{1+r}=1$, bequests are not constant (Yaari 1965). However, the arguments in this section may be easily adapted to deal with a non-zero interest rate and discounting, without affecting the basic conclusions.
} 
(recall that $r=0$ ). Without a transfer of resources between the states of the world, however, the first-best allocation is not feasible, leading to a contradiction.

Existence of the estate tax annuity identified in Proposition 1 does not depend on the lumpsum character of the tax. Therefore, even a non lump-sum estate tax provides some annuitization, although its benefits have to be weighed against the inefficiency introduced by distortionary nature of the tax policy. To see it, consider introducing a linear (distortionary) estate tax combined with the lump-sum tax. If $e$ is the proportional estate tax levy, the relevant budget constraints become ${ }^{15}$

$$
\begin{aligned}
C_{1}+B_{1}(1+e) & =y-T, \\
C_{1}+C_{2}+B_{2}(1+e) & =y-T .
\end{aligned}
$$

The solution to the consumer's problem yields the indirect utility function $w(e, T, y, p)$. The government's objective is to maximize indirect utility with respect to $e$ and $T$, subject to the revenue constraint $T+(1-p) e B_{1}+p e B_{2}=R$. In appendix, the following result is demonstrated:

Proposition 3 Starting at $e=0$, the estate tax rate should be increased.

The proposition states that introducing a positive estate tax rate (holding revenue constant) increases welfare, at least in some neighborhood of $e=0$. The intuition for this result is as follows. The excess burden of the tax increases with the square of the estate tax rate, and thus it is negligible for small tax rates. Therefore, the lump-sum approach of Section 3 applies: the only role that estate taxation plays is the provision of an actuarially fair annuity and therefore it is beneficial. From the proof, it can be seen that it is the implicit annuity that drives this result: the benefit from increasing the estate tax rate at zero is proportional to $B_{1}-B_{2}$ which, by proposition 1 , is the marginal change in annuity provided by the estate tax $\left(e B_{1}-e B_{2}\right)$. Because lump-sum taxation is feasible, other taxes should be used to the extent that they help to address market imperfections.

\section{Are Actual Policies Optimal?}

Having established a potential role for estate taxation in providing longevity insurance, one might ask if this effect is of any importance in practice. The purpose of this section is to tackle this issue by, (1) using Propositon 1 to quantify the annuity provided by the estate tax, and then by (2) evaluating the impact of insurance effect on the marginal cost of the estate tax. To accomplish the second task, I derive and calibrate a necessary first-order condition characterizing the optimal general estate tax. The focus is on the tradeoff between the beneficial effects of insurance that have been analyzed so far and the efficiency loss due to behavioral response.

\footnotetext{
${ }^{15}$ Prices of consumption in both periods are normalized to one. This rules out a possibility of imposing an agedependent consumption tax. A uniform consumption tax may still be used but it is redundant.
} 
Table 1: Annuity Payments Embedded in the U.S. Estate Tax

\begin{tabular}{ccccc}
\hline \hline & & \multicolumn{3}{c}{ Real Interest Rate } \\
& & $3 \%$ & $4 \%$ & $5 \%$ \\
\hline \multirow{3}{*}{ Initial estate } & 1.5 million & $3.1-3.7$ & $4.5-6.0$ & $5.9-8.2$ \\
& 5.0 million & $43.4-46.0$ & $59.2-65.0$ & $74.8-83.9$ \\
& 10.0 million & $98.0-103.0$ & $133.1-144.2$ & $168.0-185.4$ \\
\hline
\end{tabular}

The table shows ranges of annuity payments embedded in the streams of estate tax payments of an individual with a given initial gross estate at age of 50 . All annuity payments are in thousands of dollars.

\subsection{Converting Actual Estate Taxes to Annuities}

Proposition 1 provides a simple method of calculating the annuity embedded in the estate tax: the implicit annuity payment provided in period $s$ is simply equal to $A_{s}=(1+r) E_{s-1}-E_{s}$. An estate tax liability that is falling with age, in the present-value sense, corresponds to positive annuities. Ceteris paribus, annuity payments are higher, the faster wealth decreases in the retirement.

The calculations require assumptions about the shape of wealth profiles. In their analysis of effects of marginal estate tax rates on the size of estates at death, Kopczuk and Slemrod (2001) regressed the logarithm of gross reported estate on a number of explanatory variables, including age and age squared. The estimated age profile of gross estates ${ }^{16}$ is $\ln ($ estate $)=$ constant $-0.001321 *$ Age $+0.000028696 * A_{g e} e^{2}$ I report the results for individuals between ages of 50 and 100; in this range estates are rising (at an increasing rate) but at rates not exceeding $0.5 \%$ per year. Individuals who are 100 years old have estates that are about $16 \%$ higher than those who are 50 . I assume that deductions constitute a constant fraction of estate as taxpayers age (further details of the empirical procedure are in the appendix). The actual U.S. estate tax rate structure as of 2002 is applied to this path of wealth to convert it into the path of estate tax liabilities.

Table 1 presents calculations of the annuities embedded in the estate tax while varying two parameters: the initial (at age 50) level of estate and the interest rate. Annuities are changing over time both due to the changing slope of the wealth profile and (slightly) due to the progressivity of the estate tax. For this reason, Table 1 presents ranges of implied annuities received over the remaining lifetime. They do not, however, vary too much. For individuals with one and a half million dollars

\footnotetext{
${ }^{16}$ There is a large literature interested in estimating the shape of wealth profiles that typically finds flat or decreasing profiles (for a survey, see Hurd 1997). However, Kopczuk and Slemrod (2001) is the only paper that explicitly deals with the population of estate taxpayers and obtains results for gross estates. In the light of the Proposition 1 , a more downward sloping wealth profile corresponds to higher annuities. Therefore, my assumption is likely to be a conservative one.
} 
of gross at the age of 50 , the estate tax implicitly provides an annuity of $\$ 3,000$ to $\$ 8,000$ a year. If there were no behavioral response to estate taxation, this would mean that the estate tax acts like an increase in Social Security benefits of that amount, with an offsetting adjustment in the initial lump-sum tax liability in order to hold the expected present value of revenue constant. For higher levels of estates, the implied annuity increases both absolutely and proportionally, reaching more than $\$ 100,000$ a year for people with initial gross estate of $\$ 10,000,000$. This is due to the average tax rate increasing with the size of estate. ${ }^{17}$ In order to interpret these numbers correctly, recall that Proposition 1 determines not only annuity payments but also the corresponding initial tax. The annuity income listed in Table 1 is exactly offset by the initial tax, so that the expected net present value of tax payments is zero. The numbers in Table 1 reflect the magnitude of longevity insurance that is provided, but do not correspond to a net financial transfer to the estate taxpayers.

Although there is an annuity embedded in the estate tax, it need not be valued by taxpayers. Valuation of this annuity is analyzed in the following section.

\subsection{Marginal Cost of Estate Tax}

The linear tax model of Section 3.1 may be easily extended to account for a number of other important features, and can yield a simple test of the optimality of current policies. Denote the estate tax schedule by $E(B)+e B$, where $E(B)$ is some reference estate tax function (e.g., the actual one) and $e$ is a policy parameter. The problem is to select the optimal level of $e$. Evaluating the resulting conditions at $e=0$ provides a test of the optimality of the reference tax schedule. ${ }^{18}$ The optimal estate tax must solve

$$
\max _{e} w(e)+\lambda(Z(e)+R(e))
$$

where $w(e)$ is the indirect utility function, $Z(e)$ is expected estate tax revenue, and $R(e)$ is revenue from other taxes (which is a function of $e$ because other tax bases will generally be affected by the choice of the estate tax rate). The individual optimizes subject to a sequence of budget constraints

$$
\begin{aligned}
C_{0}+\left(B_{0}-I_{0}\right)+E\left(B_{0}\right)+e B_{0} & =W_{0}, \\
C_{i+1}+\left(B_{i+1}-I_{i+1}\right)+E\left(B_{i+1}\right)+e B_{i+1} & =(1+r)\left(B_{i}-I_{i}+E\left(B_{i}\right)+e B_{i}\right)+A_{i+1}
\end{aligned}
$$

\footnotetext{
${ }^{17}$ This effect is somewhat toned down by higher deductions at higher estate levels. Note also that it is assumed that age profile of gross estates does not vary with the size of initial estate and thus it is not responsible for differences.

${ }^{18}$ This choice of specification has a practical advantage: the "virtual income" part of the tax at any $B$ does not depend on $e$, so that to evaluate the resulting conditions one only needs to know the uncompensated tax elasticity. One can demonstrate that only functions of the form $E(B, e)=E(B)+f(e) B$ have this property.
} 
where $W_{0}$ are funds available for consumption in period $0, I_{i}$ represents payments conditional on death at the end of period $i$, such as life insurance, ${ }^{19}$ and $A_{i}$ is any additional income available if one survives until period $i . A_{i}$ may include publicly provided Social Security payments, private annuity income, income from labor supplied in a given period etc., and $W_{0}$ may be reduced by, e.g., any private life insurance or annuity purchases. The right-hand side of equation (10) represents income available in period $i+1$. The consumer has at his disposal funds that would have become his estate, had he died a period earlier, plus any funds conditional on survival. These resources have to be allocated between bequests and consumption. The payouts from life insurance increase bequests, but are not financed from current funds so that the individual chooses bequests net of life insurance. These payments are, however, taxable so that the estate tax is due on the estate inclusive of the life insurance payments. ${ }^{20}$ These equations generalize constraints given by equations (6)-(7).

One crucial piece of information necessary to characterize the solution to the government's problem (8) is $w_{e}$ : the derivative of the indirect utility function with respect to $e$. Solving equations (9)-(10) for consumption in different periods, substituting the results into the utility function, and using the envelope theorem yields

$$
w_{e}=-B_{0} u_{0}^{\prime}\left(C_{0}\right)+\sum_{i=1}^{I}\left((1+r) B_{i-1}-B_{i}\right) p_{i} u_{i}^{\prime}\left(C_{i}\right) .
$$

In deriving this expression, the utility function was assumed to be additively separable in consumption, but the instantaneous utility may vary with age, allowing for the possibility of discounting. It also should be noted that this formula does not depend on whether the variables $A_{i}, I_{i}$ and $W_{i}$ were exogenous or endogenous, and there well might have been other arguments of the utility function (such as leisure). It is the envelope theorem that allows to ignore all those other effects. ${ }^{21}$

Observe that $(1+r) B_{i}-B_{i+1}$ is the marginal change in the estate tax annuity identified in Proposition 1. Formula (11) is simply the value of this annuity stream to the individual, and there is no other effect of the estate tax on the utility of the individual that matters. This confirms that the analysis up to this point did not miss any important aspect of this tax. In order to fully

\footnotetext{
${ }^{19}$ Another interpretation of $I$ is as (minus) tax deductions with $B$ interpreted then as the taxable part of bequest.

${ }^{20}$ In practice, life insurance proceeds are usually included in the decedent's gross estate. There are exceptions, however. Bernheim (1987a) argues that life insurance provided as a fringe benefit by a corporation may escape estate taxation. Schmalbeck (2001) describes an estate tax avoidance strategy using insurance trusts.

${ }^{21}$ To be more explicit, suppose that the instantanous utility was given by $u_{i}(C, X)$ where $X$ is the vector of all other relevant endogenous variables, possibly including leisure. Allow variables in $X$ to determine $W_{0}, A$ 's and $I$ 's in the budget constraint through arbitrary functional forms $W_{0}(X), A(X), I(X)$. As long as the estate tax rate does not enter $W_{0}(\cdot), A(\cdot)$ and $I(\cdot)$, the envelope theorem implies expression 11 with $\frac{\partial u_{0}}{\partial C}, \frac{\partial u_{i}}{\partial C}$ taking place of $u_{0}^{\prime}$ and $u_{i}^{\prime}$. All the subsequent analysis of the welfare impact of a change in the estate tax rate also goes through, so that my calibration of the numerator of equation 15 is not affected by such generalizations.
} 
analyze the optimal estate tax, the effect of estate taxation on the individual utility level has to be compared with its impact on the tax revenue.

Observe one more result. If annuity markets operate, actual annuity prices provide the information necessary to evaluate expression (11). More specifically, assume that in period zero the individual may purchase a contingent claim that will pay out $\$ 1$ in period $i$ conditional on survival, at the price of $p_{A i}$, where $p_{A i} \geq \frac{p_{i}}{(1+r)^{i}}$. If $p_{A i}=\frac{p_{i}}{(1+r)^{i}}$, the price is actuarially fair. This possibility is implicitly present in the framework given by equations (9)-(10): purchases of annuities may be included in $W_{0}$ and the payouts accounted for in $A_{i}$. It is straightforward to show that at the optimum the following must be true,

$$
u_{0}^{\prime}\left(C_{0}\right) \geq \frac{p_{i}}{p_{A i}} u_{i}^{\prime}\left(C_{i}\right)
$$

with equality whenever a positive amount of actuarial claims is purchased. If individuals purchase annuities, their prices reveal information about the marginal utilities, and equation (11) leads to

$$
\frac{w_{e}}{u_{0}^{\prime}\left(C_{0}\right)}=-B_{0}+\sum_{i=1}^{I} p_{A i}\left((1+r) B_{i-1}-B_{i}\right) .
$$

Note that this formula does not depend on mortality rates directly, although they are presumably reflected in the equilibrium values of $p_{A i}$ 's. ${ }^{22}$ The right-hand side of this formula may be evaluated empirically. This is the value of the annuity contract identified in Proposition 1 at the actual market prices of annuities. For the purpose of assessing the optimality of the actual tax system, evaluation of this formula requires only knowledge of the actual time-pattern of bequests and the actual annuity prices, both of which are potentially observable. Such calculations are presented below. It needs to be stressed that this formula applies only when individuals are not constrained in their annuity choices. Bernheim (1987b) argued that most of the annuity contracts are purchased through employers, and that most individuals cannot adjust their annuity holdings at the margin. On the other hand, Mitchell, Poterba, Warshawsky, and Brown (1999) observe that annuity markets were rapidly expanding during the 1990s, so that this may no longer be a bad assumption. The calculations that follow overestimate the value of annuities for people who do not buy annuities.

The necessary condition for the optimal level of $e$ follows from differentiating equation (8):

$$
\frac{w_{e}}{u_{0}^{\prime}\left(C_{0}\right)}+\frac{\lambda}{u_{0}^{\prime}\left(C_{0}\right)}\left(\frac{\partial Z}{\partial e}+\frac{\partial R}{\partial e}\right)=0
$$

As demonstrated above, the first term is equal to the market value of the annuity contract provided by the estate tax policy. The term $\frac{\lambda}{u_{0}^{\prime}\left(C_{0}\right)}$ is the marginal cost of funds when other tax instruments

\footnotetext{
${ }^{22}$ Mullin and Philipson (1997) assume no imperfections in the life-insurance market and use the data on prices of contingent claims to estimate future mortality hazard rates.
} 
are used, so that the second component of the formula is simply the social value of the revenue collected due to a marginal change in tax policy. The relevant revenue effect has to account not only for the estate tax revenues, but also for a potential effect of the estate tax rate change on other sources of revenue.

Equation (14) implies that the marginal cost of funds for the estate tax must at the optimum be equal to the marginal tax for other instruments, denoted $M C F$ below.

$$
M C F_{e} \equiv-\frac{w_{e} / u_{0}^{\prime}\left(C_{0}\right)}{\frac{\partial Z}{\partial e}+\frac{\partial R}{\partial e}}=\frac{\lambda}{u_{0}^{\prime}\left(C_{0}\right)} \equiv M C F
$$

When the actual tax system is not optimal, the relationship between $M C F_{e}$ and $M C F$ indicates whether the estate tax should be increased or decreased: if the marginal cost of using it is lower than that of the alternative ways of collecting revenue, the estate tax rate should be increased and vice versa. There are estimates in the literature of the marginal cost of funds for e.g., the income tax, and they can be compared to the value of $M C F_{e}$.

\subsection{Calibration}

The numerator of the $M C F_{e}$ in formula (15) may be evaluated using expression (13). It requires knowledge of the pattern of annuity prices. Rather than use the empirical path of annuity prices directly, I rely on the estimates of Mitchell, Poterba, Warshawsky, and Brown (1999), who computed the measure of the "money's worth" of annuities. They calculated (presented in their Table 3) the expected present discounted value of the actual annuity policies' payouts per premium dollar (which will be denoted by $\beta$ ). Under actuarially fair prices, this should be equal to one: the whole transaction should have an expected value of zero. When annuities are not fairly priced, this value is below one. Their maximum estimate of $\beta$ is 0.927 . In terms of prices of annuity claims $p_{A i}$, $\beta$ is assumed to correspond to $p_{A i}=\beta^{-1}(1+r)^{-i} p_{i}$, i.e., the annuity prices being $\beta^{-1}$ times higher than the actuarially fair prices. Of course, the mark-up may vary over time, but in this stylized setting it is convenient to have a single measure of the inefficiency of insurance markets. ${ }^{23}$

Given the initial level of wealth, the age profile of taxable bequests necessary to evaluate expression (13) is calculated using estimates from Kopczuk and Slemrod (2001) and the actual

\footnotetext{
${ }^{23}$ In practice, it is not possible to purchase one-period annuity claims. Instead, individuals have to purchase longerterm contracts. Provided that an annuity with the pattern implicitly provided by the estate tax can be purchased, on the margin it should be valued at the actual market price and the approach remains valid. If it is not possible to construct an analogous annuity using instruments available in the market, no price that could be used to make this valuation arises and the approach yields only an approximation of the actual benefit. There are reasons to believe that this approach may result in an underestimation of the value of the implicit annuity: estate tax yields a real annuity and such instruments are not available in the United States (Diamond 1977; Brown, Mitchell, and Poterba 2000) but potentially could be beneficial.
} 
estate tax schedule as of 2002, as in Section 4.1. For now, I assume that $\frac{\partial R}{\partial e}=0$, i.e., that the estate tax has no effect on revenue from other sources. The denominator of $M C F_{e}$ is then equal to (when evaluated at $e=0): \frac{\partial Z}{\partial e}=\sum\left(p_{i}-p_{i+1}\right)(1+r)^{-i}\left(B_{i}+E^{\prime} \frac{\partial B_{i}}{\partial e}\right)$. Values of $B_{i}$ follow from the assumed estate profile and the $E^{\prime}$ 's are the corresponding empirical marginal tax rates. The strength of the behavioral response, $\frac{\partial B_{i}}{\partial e}$, can be calculated using the elasticity of estates $(\epsilon)$ with respect to the tax price $\left(1-E^{\prime}\right)$. The formula is derived in the appendix. Kopczuk and Slemrod (2001) estimated $\epsilon$, and came up with a baseline estimate of $0.094 .^{24}$

The final piece of information necessary to calculate the $M C F_{e}$ are mortality rates. Two alternatives are considered. One is the population life table from the Social Security Administration (1992). The other one is the annuity life table, based on the mortality experience of pension plans (Society of Actuaries 2000). The annuity life tables are usually thought to be more representative of the mortality experience of the wealthy, because annuitants tend to be wealthier. The population life tables contain a separate life table for cohorts born every five years, and the appropriate cohort life table is used in what follows. The annuity life table is based on the actual mortality experience between 1990 and 1994, but does not account for the cohort effect. It is used as is. As reported below, the results are not too sensitive to the choice of mortality rates.

The value of the $M C F_{e}$ is calculated for a male who was 65 years old in 1995 . These assumptions match calculations in the Mitchell, Poterba, Warshawsky, and Brown (1999) study. Individuals with initial taxable estates of $\$ 1.5$ million, $\$ 5$ million and $\$ 10$ million. The values of $M C F_{e}$ are calculated for the interest rates of $3 \%$ and $5 \%$, net-of-tax elasticities equal to $0.0,0.094$ and 0.3 , and three levels of the strength of the annuity market imperfection: $\beta=1, \beta=0.927$ and $\beta=0.756$. The first value of $\beta$ corresponds to the case of perfect insurance markets. The other two values are the highest and the lowest estimate of $\beta$ from Mitchell, Poterba, Warshawsky, and Brown (1999) for 1995. ${ }^{25}$ Additional details of computations are discussed in the appendix.

The results are reported in Table 2 . When $\beta=1$, they represent the upper bound for the $M C F_{e}$ if individuals are not overannuitized: the annuities are priced at the actuarially fair rates. Not surprisingly, the $M C F_{e}$ increases with $\epsilon$ (i.e., with the strength of behavioral response) and it decreases as $\beta$ falls (i.e., the stronger are imperfections in the annuity markets) because the annuities become more valuable. A higher interest rate reduces the $M C F_{e}$ because it increases the importance of the future and, therefore, the value of providing annuities. Finally, higher wealth acts to increase the value of $M C F_{e}$, reflecting stronger distortions caused by higher marginal tax

\footnotetext{
${ }^{24} \mathrm{~A}$ positive value corresponds to higher tax rates reducing the estate. When the estate tax elasticity is constant, the bequest elasticity is a function of the marginal tax rate. For the actual U.S. estate tax rates, it corresponds to the bequest elasticity of between 0.4 and 0.7 .

${ }^{25}$ The high value of $\beta$ was calculated using the actuarial life table and the expected rates of return based on the Treasury bond yield curve, while the low value corresponds to the population life table and the returns based on the corporate yield curve.
} 
rates. This effect turns out to dominate the effect of providing a bigger annuity. The estimates are lower when the actuarial life tables are used, but the difference in results from using the two mortality assumptions is very small.

When compared to the perfect insurance markets case, the presence of market imperfections contributes to a reduction in the $M C F_{e}$ by $4-8 \%$ for the high value of $\beta$ and $16-35 \%$ for the low value of $\beta$. When the empirically based values of parameters are used $(\epsilon=.094, \beta<1)$, the $M C F$ does not exceed 2.2 and the estimates of the $M C F$ for the lowest considered level of estate do not exceed 1.8. The $M C F$ is as low as 1.2 under strong imperfections and the lowest considered level of estate. ${ }^{26}$ These values of $M C F_{e}$ are within the range of estimates of the $M C F$ for the income tax known from the literature that vary between 1.35 and about 3.0. ${ }^{27}$ Both ranges of estimates are wide and do not suggests that the estate tax is clearly inferior to other tax instruments present in the federal tax system.

Table 2 indicates that results depend on the strength of tax leakage effect $(\varepsilon)$. The evidence that I relied on pertains to the tax elasticity of gross estates. If deductions are responsive to marginal tax rate changes, the relevant elasticity is bigger. On the other hand, it is likely that estate taxation affects the revenue from other sources. To the extent that higher estate tax rates increase revenue from other sources, the relevant elasticity is lower than assumed. Most importantly, estate taxation closely interacts with capital income taxes. Bernheim (1987a) argued that when this effect is accounted for, the net revenue collected by the estate tax is close to zero when compared to the alternative of removing the estate tax and repealing the step-up of capital gains basis at death. In other words, the current tax system has a similar impact on revenue as the system that would use only capital income taxation. This does not, however, provide direct information about the effect of marginal estate tax rate on capital tax revenue. Estates decreasing with the tax rate $(\epsilon$ positive) may correspond to increased tax avoidance, but it may also correspond to a real response. In particular, it may correspond to substitution toward more lifetime consumption or more leisure. The first of these gives rise to more income from sales taxes and also more capital tax revenue as more capital gains need to be realized. Substitution toward leisure, on the other hand, reduces labor income taxes. The picture is further complicated by income responses. Therefore, theory cannot unambiguously establish the sign $\frac{\partial R}{\partial e}$. The complete analysis of the impact of the estate tax on tax revenue requires further empirical work.

\footnotetext{
${ }^{26}$ The population $M C F$ is an average (possibly weighted) of the individual $M C F$ 's and the estate tax paying population (and higher redistributive weights) is concentrated at the lower end of the distribution.

${ }^{27}$ This is obtained from a linear model of optimal income taxation. The $M C F$ is equal to $\frac{1}{1-\frac{t}{1-t} \varepsilon}$, where $\varepsilon$ is the elasticity of taxable income with respect to the net-of-tax rate. Most of the studies find elasticities between .4 and 1. Recent references in this literature include Auten and Carroll (1999); Gruber and Saez (2002). With the top marginal income tax rate of 0.39 this corresponds to a $M C F$ between 1.34 and 2.77 .
} 


\section{Extensions and Conclusions}

Estate taxes contain an implicit annuity, which should be welcome when insurance markets faced by individuals subject to estate taxation are imperfect, as is arguably the case in practice. Eliminating the tax and replacing it by other taxes designed to collect the same amount of revenue from the same people may actually reduce the welfare of these individuals, even if the alternative taxes are completely non-distortionary. If the true goal of a reform is to reduce the burden imposed on the rich, it may be better achieved by reducing taxes other than the estate tax, so that the annuities embedded into it are not eliminated.

According to my calibration results, the current estate tax is arguably no more inefficient than the current income tax. This paper does not address, however, another intriguing issue of whether the estate tax should be a part of the fully optimal tax system, but rather points to its previously ignored insurance benefit that should be taken into account in any such analysis. Given that many instruments correcting insurance imperfections are possible, one might ask whether estate taxation can add anything to this arsenal. The answer to this question is likely to depend on the economic environment and the source of market failure. For example, with binding liquidity or borrowing constraints, paying for annuities ex post (as with estate taxation) is preferred to paying ex ante (as with Social Security). Administrative costs of different solutions may possibly be different. If there is moral hazard in annuity markets (see, Davies and Kuhn 1992; Philipson and Becker 1998), estate tax is likely to fare no better than Social Security because it does not address the underlying issue of endogenous health investments. It is also possible that various insurance instruments should be simultaneously present in the optimal system. In the earlier version of this paper (Kopczuk 2001), I showed that both Social Security and estate tax should be used to provide longevity insurance in a redistributive model with adverse selection in the insurance markets arising due to private information about mortality. In that context, Social Security cannot insure completely and the incremental annuity provided by the estate tax is useful.

The analysis has some important consequences for evaluating the efficiency of estate taxation. Usually, inefficiency of a tax is measured by the strength of its response to a change in the marginal tax rate. This is not sufficient with estate taxation, because it also provides a benefit that other instruments do not: insurance against longevity. A complete evaluation must then account for these additional efficiency gains. Therefore, analyses of estate taxation that concentrate on its distortions or its redistributive properties, (e.g., Poterba 2000; Kopczuk and Slemrod 2001) paint only part of the picture.

One of the implications of the paper is that the routine assumption of confiscating accidental bequests often made when OLG models are simulated is not innocuous. This is especially relevant when one is interested in simulating effects of Social Security reform, because assumptions about the treatment of accidental bequests affect the amount of implicit annuitization provided by the tax code and therefore the benefits to other forms of longevity insurance. Further work is required to 
understand the importance of such assumptions and other dynamic consequences of estate taxation. The annuity effect of estate tax likely acts to increase national saving because it leads to an increase in saving-financed consumption late in life. Although it seems intuitive that distortionary aspect of actual estate taxation reduces saving, ${ }^{28}$ Gale and Perozek (2001) demonstrate that the response is theoretically ambiguous. At a longer horizon, the distribution of wealth will also be affected by estate taxation (see e.g., Stiglitz 1978).

Although this paper has addressed estate taxation, there are other taxes that interact with life-long financial security. For example, the sales tax is conditional on being alive (the opposite of estate taxation), and therefore it aggravates the problems caused by imperfect insurance markets. Unlike the estate tax, sales tax affects the whole population. Other taxes, such as annual wealth taxes are neutral with respect to this problem, because they are imposed regardless of the resolution of uncertainty. A similar argument applies to labor income taxation: most of the income subject to this tax is earned during the working years, when mortality rates are very low. The key observation of this paper is that lifetime taxes falling with the realized length of life provide an annuity. This argument should be weighed against a more standard view that taxes occurring late in life are preferred because young people are more likely to be subject to borrowing constraints. Depending on the strength of imperfections in the annuity markets, the insurance considerations may play an important role in determining the optimal structure of taxation.

\footnotetext{
${ }^{28}$ Empirical results of Kopczuk and Slemrod (2001) appear to indicate so. However the behavioral response that they find is the response of reported gross estate. In the presence of tax avoidance, it need not be the same as response of wealth accumulation.
} 


\section{A. Appendix}

Lemma 1. Proof: Suppose that the consumption/bequest paths before period $s$ are identical. Consider choosing the same consumption in period $s$ in both cases. Conditional on death in period $s$, the tax of $E_{s}$ is due in both cases. Therefore, bequests conditional on having died in period $s$ are identical. Conditional on having survived until period $s+1$, the present value of the tax liability is zero in each case. Therefore, resources available at the beginning of period $s+1$ are identical in each case and the identical consumption/bequest plans can be implemented from that point on.

Proposition 3. Proof: The individual constraints can be used to solve for $C_{1}$ and $C_{2}$, so that the problem of the individual is to maximize

$$
u\left(y-T-B_{1}(1+e)\right)+(1-p) v\left(B_{1}\right)+p v\left(B_{2}\right)+p u\left((1+e)\left(B_{1}-B_{2}\right)\right) .
$$

with respect to $B_{1}$ and $B_{2}$. By the envelope theorem, $w_{e}=-B_{1} u^{\prime}\left(C_{1}\right)+p\left(B_{1}-B_{2}\right) u^{\prime}\left(C_{2}\right)$ and $w_{T}=-u^{\prime}\left(C_{1}\right)$. Define $X \equiv(1-p) B_{1}+p B_{2}$, so that the revenue constraint is $T+e X=R$.

Note that the government's problem may be expressed as unconstrained maximization with respect to $e$, with $T(e)$ implicitly defined by the revenue constraint. It is straightforward to show that the first-order effect on welfare is, denoting $\gamma=\frac{u^{\prime}\left(C_{2}\right)}{u^{\prime}\left(C_{1}\right)}$,

$$
u^{\prime}\left(C_{1}\right)\left(-B_{1}+p\left(B_{1}-B_{2}\right) \gamma+\frac{X+e \frac{\partial X}{\partial e}}{1+e \frac{\partial X}{\partial T}}\right) .
$$

Locally, if this expression is positive, the estate tax rate should be increased. Evaluate it at $e=0$ and normalize dividing by always positive $u^{\prime}\left(C_{1}\right)$. Then, it reduces to $p\left(B_{1}-B_{2}\right)(\gamma-1)$. The individual first-order conditions are

$$
\begin{aligned}
(1-p) v^{\prime}\left(B_{1}\right)+(1+e)\left(p u^{\prime}\left(C_{2}\right)-u^{\prime}\left(C_{1}\right)\right) & =0 \\
p v^{\prime}\left(B_{2}\right)-(1+e) p u^{\prime}\left(C_{2}\right) & =0 .
\end{aligned}
$$

These equations may be combined to eliminate $1+e$ yielding,

$$
\frac{1}{\gamma}=\frac{u^{\prime}\left(C_{1}\right)}{u^{\prime}\left(C_{2}\right)}=p+(1-p) \frac{v^{\prime}\left(B_{1}\right)}{v^{\prime}\left(B_{2}\right)} .
$$

If $B_{1}>B_{2}$, then $\gamma>1$, and if $B_{1}<B_{2},{ }^{29}$ then $\gamma<1$ so that $p\left(B_{1}-B_{2}\right)(\gamma-1)$ is always positive. Therefore, the estate tax rate should be increased. Note that this immediately implies that there is a local maximum with $e>0$ (possibly at a corner $e=1$ ), but it does not rule out the possibility of a local maximum with $e<0$.

Formula for Bequest Elasticity. Denote the total estate at age $i$ by $S_{i}=B_{i}+E\left(B_{i}\right)+e B_{i}$. This leads to (when evaluated at $e=0$ ), $B_{i}+E^{\prime} \frac{\partial B_{i}}{\partial e}=\frac{E^{\prime}}{1+E^{\prime}} \frac{\partial S}{\partial e}+\frac{B}{1+E^{\prime}}$. Kopczuk and Slemrod (2001)

\footnotetext{
${ }^{29}$ Constraints (6) and (7) imply that $B_{1}>B_{2}$, but the proposition does not rely on this. It would still apply if individuals were overannuitized, with the estate tax inducing a negative annuity.
} 
estimate the elasticity of gross estate with respect to the net-of-tax rate, i.e., $\epsilon \equiv \frac{(1-x) \frac{\partial S}{\partial(1-x)}}{S}$, where $x$ is the marginal estate tax rate, which is related to $E^{\prime}$ by $x=\frac{E^{\prime}}{1+E^{\prime}}$. Therefore, $\frac{\partial S}{\partial x}=\frac{\partial S}{\partial E^{\prime}} \frac{\partial E^{\prime}}{\partial x}=$ $\frac{1}{(1-x)^{2}} \frac{\partial S}{\partial E^{\prime}}$. Note that $\frac{\partial S}{\partial E^{\prime}}=\frac{\partial S}{\partial e}$ and $\frac{\partial S}{\partial x}=-\frac{\partial S}{\partial(1-x)}$, so that $\frac{\partial S}{\partial e}=-(1-x) S \epsilon$. Consequently, $B_{i}+E^{\prime} \frac{\partial B_{i}}{\partial e}=-x(1-x) S \epsilon+(1-x) B$. Here $x$ is the (empirical) estate tax rate and $\epsilon$ is the elasticity as estimated by Kopczuk and Slemrod (2001).

Empirical Assumptions. Estate tax structure as of 2002 is used. ${ }^{30}$ If taxable estate is below $\$ 1$ million, no tax is due. The initial marginal tax rate is $41 \%$, and it quickly rises to the maximum value of $50 \%$ at $\$ 2.5$ million level. I assume that the share of deductions in gross estate does not change with age. This assumption also implies that the elasticity of gross estate is equal to the elasticity of taxable estate. In computation of $M C F_{e}, B+E(B)$ is taken to be equal to gross estate net of tax deductions. As explained in footnotes 19 and 21, the derivation of $M C F_{e}$ is not affected by such reinterpretation. The following shares of deductions are used for $\$ 1, \$ 5$ and $\$ 10$ million initial gross estates: $11.53 \%, 14.66 \%$ and $18.83 \%$, respectively. These numbers correspond to shares of deductions on the tax returns filed in 1998 for single or widowed taxpayers in gross estate brackets of $\$ 1-\$ 5$ million, $\$ 5-\$ 10$ million and $\$ 10-\$ 20$ million. This information is based on unpublished tabulations provided by Barry Johnson of the IRS. Widowed or single taxpayers were selected because in the same data $59 \%$ of estates of married individuals is transferred tax free to their spouses using unlimited marital deductions. Spousal transfers are likely subject to taxation at death of the surviving spouse so that it is inappropriate to treat them as non-taxable. See Johnson, Mikow, and Eller (2001) for descriptive statistics related to the composition of estates, and Kopczuk and Slemrod (2002) for a discussion of marital deductions. Changes in deduction parameter that leave individuals in the same tax bracket have very little effect on $M C F_{e}$. They affect the size of annuity mechanically by changing the level of tax liability. Ideally one should use the age profile of taxable estates without making any assumptions regarding deductions. However, such information is not available. Note that if the true gross estate profile is flat (as assumed in the paper), the evidence of deductions falling with gross estate contains no information about age effects. If the share of deductions is increasing with age, tax liability falls more quickly than implied by my assumptions and I underestimate the size of annuity and overestimate $M C F_{e}$. On the other hand, if tax deductions respond to marginal tax rates, the true behavioral response is stronger and $M C F_{e}$ is underestimated.

\footnotetext{
${ }^{30}$ In the earlier version of this paper (Kopczuk 2001), tax structure as of 1999 was used. This is the main source of numerical differences in results. The qualitative conclusions are not affected.
} 


\section{REFERENCES}

Abel, A. B. (1985): "Precautionary Saving and Accidental Bequests," American Economic Review, 75(4), 777-791.

Akerlof, G. A. (1970): "The Market for Lemons: Quality Uncertainty and the Market Mechanism," Quarterly Journal of Economics, 84(3), 488-500.

Attanasio, O. P., And H. W. Hoynes (2000): "Differential Mortality and Wealth Accumulation," Journal of Human Resources, 35(1), 1-29.

Auten, G., and R. Carroll (1999): "The Effect of Income Taxes on Household Behavior," Review of Economics and Statistics, 81(4), 681-693.

Bernheim, B. D. (1987a): "Does the Estate Tax Raise Revenue?," in Tax Policy and the Economy, ed. by L. H. Summers, vol. 1, pp. 113-138. Chicago: National Bureau of Economic Research; Cambridge, Mass.: MIT Press.

(1987b): "The Economic Effects of Social Security: Toward a Reconciliation of Theory and Measurement," Journal of Public Economics, 33(3), 273-304.

(1991): "How Strong Are Bequest Motives? Evidence Based on Estimates of the Demand for Life Insurance and Annuities," Journal of Political Economy, 99(5), 899-927.

Brown, J. R., O. S. Mitchell, and J. M. Poterba (2000): "Mortality Risk, Inflation Risk, and Annuity Products," Working Paper 7812, National Bureau of Economic Research.

Davies, J. B. (1981): "Uncertain Lifetime, Consumption, and Dissaving in Retirement," Journal of Political Economy, 89(3), 561-77.

Davies, J. B., And P. Kuhn (1992): "Social Security, Longevity, and Moral Hazard," Journal of Public Economics, 49(1), 91-106.

Diamond, P. A. (1977): “A Framework for Social Security Analysis," Journal of Public Economics, $8(3), 275-298$.

Friedman, B. M., and M. Warshawsky (1990): "The Cost of Annuities: Implications for Saving Behavior and Bequests," Quarterly Journal of Economics, 105(1), 135-54.

Gale, W. G., and M. G. PerozeK (2001): "Do Estate Taxes Reduce Savings?," in Rethinking Estate and Gift Taxation, ed. by W. G. Gale, J. R. Hines Jr., and J. Slemrod. Brookings Institution Press.

Gruber, J., And E. SAez (2002): "The Elasticity of Taxable Income: Evidence and Implications," Journal of Public Economics, 84(1), 1-32.

Hurd, M. D. (1989): "Mortality Risk and Bequests," Econometrica, 57(4), 779-813.

- (1997): "The Economics of Individual Aging," in Handbook of Population and Family Economics, ed. by M. K. Rosenzweig, and O. Stark, vol. 1B, pp. 891-966. Elsevier/North Holland, Amsterdam; New York.

Johnson, B. W., J. M. Mikow, and M. B. Eller (2001): "Elements of Federal Estate Taxation," in Rethinking Estate and Gift Taxation, ed. by W. G. Gale, J. R. Hines Jr., and J. Slemrod. Brookings Institution Press.

Kopczuk, W. (2001): "Essays on Estate Taxation," Ph.D. thesis, University of Michigan. 
Kopczuk, W., And J. Slemrod (2001): "The Impact of the Estate Tax on the Wealth Accumulation and Avoidance Behavior of Donors," in Rethinking Estate and Gift Taxation, ed. by W. G. Gale, J. R. Hines Jr., and J. Slemrod. Brookings Institution Press.

(2002): "Tax Impacts on Wealth Accumulation and Transfers of the Rich," in The Role and Impact of Gifts and Estates, ed. by A. H. Munnell. Brookings Institution, Forthcoming.

Mitchell, O. S., J. M. Poterba, M. J. Warshawsky, and J. R. Brown (1999): "New Evidence on the Money's Worth of Individual Annuities," American Economic Review, 89(5), 1299-1317.

Mullin, C., And T. Philipson (1997): "The Future of Old-Age Longevity: Competitive Pricing of Mortality Contingent Claims," Working Paper 6042, National Bureau of Economic Research.

Philipson, T. J., And G. S. Becker (1998): "Old-Age Longevity and Mortality-Contingent Claims," Journal of Political Economy, 106(3), 551-573.

Poterba, J. M. (2000): "The Estate Tax and After-Tax Investment Returns," in Does Atlas Shrug? The Economic Consequences of Taxing the Rich, ed. by J. Slemrod. Harvard University Press and Russell Sage Foundation, New York.

Rothschild, M., and J. Stiglitz (1976): "Equilibrium in Competitive Insurance Markets: An Essay on Economics of Imperfect Information," Quarterly Journal of Economics, 90(4), $629-49$.

Schmalbeck, R. (2001): "Avoiding Federal Wealth Transfer Taxes," in Rethinking Estate and Gift Taxation, ed. by W. G. Gale, J. R. Hines Jr., and J. Slemrod. Brookings Institution Press.

Social Security Administration (1992): "Life Tables for the United States Social Security Area," Actuarial Study 107.

(1997): "Social Security Programs in the United States," SSA Publication No. 13-11758, Office of Research, Evaluation and Statistics, Retrieved August 25, 2000 from the World Wide Web: http://www.ssa.gov/statistics/sspus.html.

Society of Actuaries (2000): "The RP-2000 Mortality Tables," Discussion paper, Retrieved August 27, 2000 from the World Wide Web: http://www.soa.org/research/rp2000.html.

Stiglitz, J. E. (1978): "Notes on Estate Taxes, Redistribution, and the Concept of Balanced Growth Path Incidence," Journal of Political Economy, 86(2), S137-S150.

YAARI, M. E. (1965): "Uncertain Lifetime, Life Insurance, and the Theory of the Consumer," Review of Economic Studies, 32(2), 137-150. 
Table 2. Value of the Marginal Cost of Funds for the Estate Tax

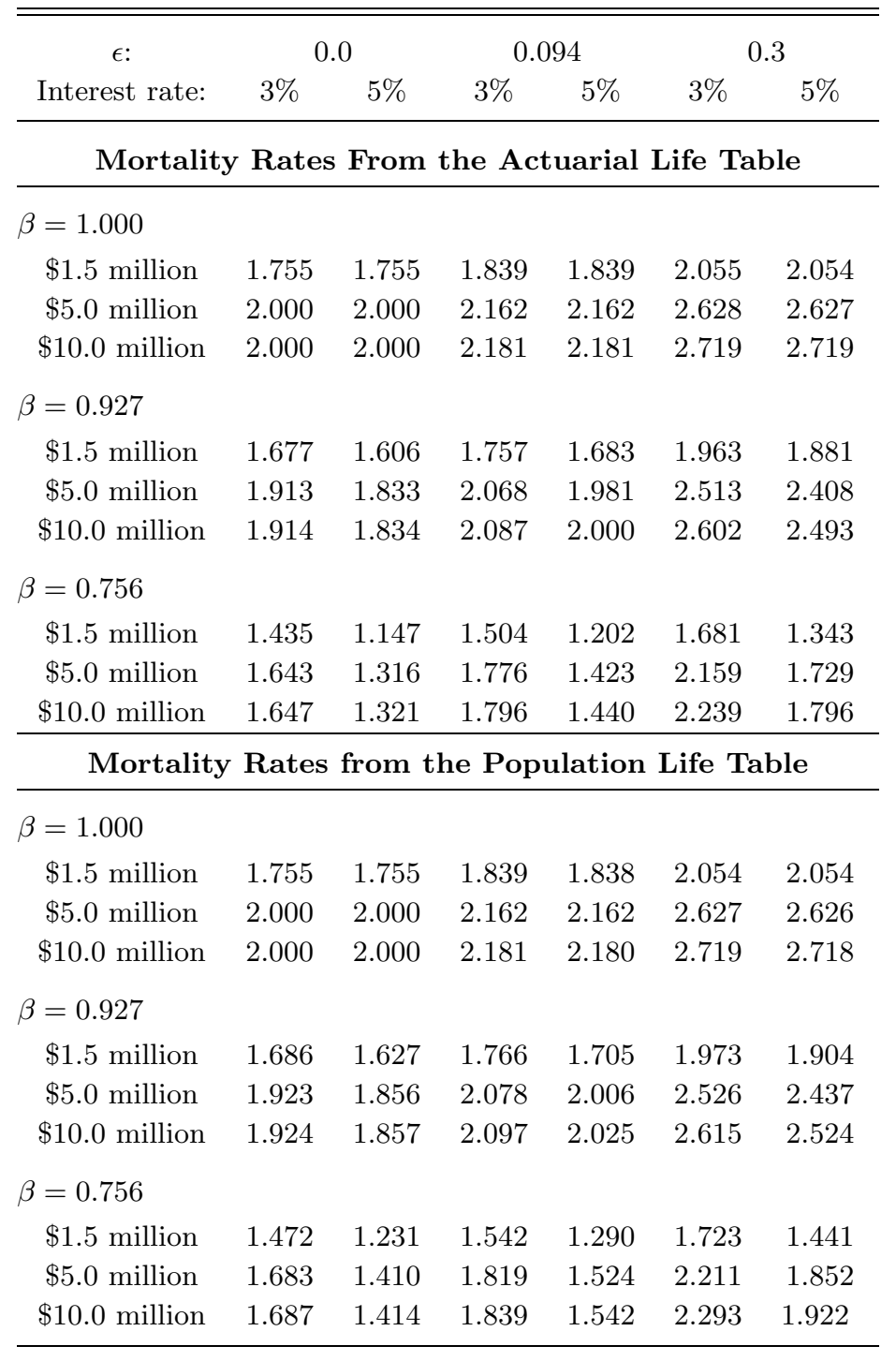

Table contains calibrated values of $M C F_{e}$ under different mortality assumptions for individuals with initial (at age 65) gross estates of $\$ 1.5$, $\$ 5$ and $\$ 10$ million, for different levels of the interest rate, tax elasticity of estates $(\varepsilon)$ and strengths of imperfections in the annuity markets $(\beta)$. 